\title{
Popular Science Discourse Development in the Cyberspace
}

\author{
Liudmila A Egorova*
}

Department of Foreign Languages in Theory and Practice, Institute of Foreign Languages, Peoples' Friendship University of Russia, 6 Miklukho-Maklaya st., 117198 Moscow, Russian Federation

Corresponding Author: Liudmila A Egorova, E-mail: egorova_la@rudn.university

\section{ARTICLE INFO}

\section{Article history}

Received: April 16, 2018

Accepted: July 19, 2018

Published: October 31, 2018

Volume: 9 Issue: 5

Advance access: August 2018

Conflicts of interest: None

Funding: None

\section{Key words:}

Popular Science Discourse,

Hypermedia Communication,

Podcast,

Multimodal Texts,

Intercultural Interaction

\begin{abstract}
Popular science sphere of communication is acquiring new features of virtuality, globality, mosaic structure and social orientation, which are essential in fulfilling its functions in modern society. Based on the examination of 92 podcasts, the study deals with podcasting research identifying typical characteristics of the podcast and factors contributing to the spread of podcasting in the popular scientific hypermedia communication. The survey showed that increasing popularity of the podcast in the popular scientific sphere is explained by several factors. First, informing the user becomes more accessible, quicker and easier. Secondly, the listener takes part in interpersonal communication not with a virtual author, but with a real person, gets the opportunity to make his own conclusions based on sounding speech, which is more expressive, emotional, and has a strong impact on the addressee. Thirdly, most podcasts are interviews and discussions, which facilitates the perception and processing of new information making it more structured by means of questions, paraphrasing, exemplification, clarifications, etc. Analysis of the Nature publication podcast helped single out structural features that allow a podcast to function in a hypermedia environment as an independent multimodal node. The conclusions about the emergence of new virtual environment for intercultural interaction and cooperation were made.
\end{abstract}

\section{INTRODUCTION}

Scientific and popular sphere of communication is now rapidly developing and gaining new features - virtuality, globality, mosaic, social orientation. The development of the scientific picture of the world, processing huge flows of information, new technologies cause a real collapse in the mass consciousness leading to a real ideological crisis. Overcoming the conceptual vacuum is the main goal of popular scientific publications (Russell, 2009).

Non-profit organizations and foundations that publish popular science magazines, books, Internet sites, television channels set global goals for the organization of the entire world community to address the interdisciplinary world problems related to environmental protection, the development of education, the protection of human rights, the intensification of medical research, etc. These are the aims of a number of projects, information, financial, scientific and technical support of which is provided by the scientific community as well as government agencies.

Creating an information multimedia network linking various sources of information contributes to the advancement of scientific and technological achievements worldwide, which is impossible without developing communication between scientists, engineers and ordinary people giving scientists the opportunity to influence society and society to influence the scientific world (Sava, 2011, Gürsul, F., \& Canim, S., 2013; Pearce \& Scutter, 2010).

Podcasting has recently gained particular popularity, especially in scientific and academic spheres of communication (Gürsul \& Canim, 2013; Ono \& Ishihara, 2010).

Podcast (derived from iPod and broadcast) is a digital media file distributed over the Internet (usually an mp3 audio file) or a group of files that can be played back using a computer or a portable media player, a car stereo, a mobile phone, and a home stereo system.

The most important advantages of podcasting are standardized format, regular updating of content (seriality) and free subscription. The main difference between podcasting and other ways of distributing digital audio and video is its standardization based on the RSS Protocol. Standardization makes it possible to unify programs created by different authors, regardless of their specific content. Another distinctive feature is the dynamic nature of podcasting, i.e. the frequency of programs. This contrasts sharply with one-time publications of any multimedia materials. Another important reason for the widespread use of podcasting is that all programs are fundamentally free for listeners, and the procedure of subscription and its subsequent changes is quite simple. 
"From the point of view of users, standardization and dynamics are important because they can subscribe to any number of RSS-channels that publish materials on topics of interest to these users at different intervals. Standardization makes it possible to simply combine (syndicate) different sources, whereas dynamics contributes to the development of selected topics over time" (Stupina, 2007:4-5).

Another feature of a podcast is its fundamental dialogical character. Podcast is dialogic both implicitly, in the sense of M. M. Bakhtin, in connection with direct and indirect references to the context, and explicitly - each block is a polylogue among several speakers, moreover, each reply is addressed to the listeners making them direct participants of the communication (Stupina, 2007; King \& Gura, 2009; Gürsul \& Canim, 2013).

\section{AIMS OF THE RESEARCH}

The objectives of this research were as follows:

- to analyze the factors contributing to the spread of podcasting in the popular scientific hypermedia communication;

- to identify typical characteristics of a podcast in the area;

- to examine the Nature podcast edition and single out its structural features that allow the podcast to function in a hypermedia environment as a separate multimodal node;

- $\quad$ to assess the implementation of podcasting in translators and interpreters training.

Therefore, the research consisted of three experimental studies directed at fulfilling different tasks.

\section{EXPERIMENTAL STUDY 1}

\section{Methods and Materials}

92 popular science podcasts were examined to identify typical characteristics of the podcast and factors contributing to the spread of podcasting in the popular scientific hypermedia communication.

\section{Results and Discussion}

The features of a typical podcast format in this area were identified. So, this is

- $\quad$ an audio podcast (video podcasts are about $6 \%$ )

- lasting on average 20 minutes (the range is from $1 \mathrm{~min}-$ ute to 1 hour),

- regularly updated (once a week $-30 \%$, daily - 5\%) or released in form as a series of episodes (about 35\%).

- $77 \%$ of podcasts are fundamentally polythematical, $23 \%$ are devoted to developments in one scientific field.

- $36 \%$ of the (mostly regularly published) podcasts include news about the most important research with commentaries,

- $57 \%$ - interviews, round table discussions on a topic (discovery, problem, research).

- To attract the listener, the authors focus their attention on the topical issues that are important for humanity (15\%), invite famous scientists or leading (10\%), use interactive mode $(5 \%)$, humorous comment $(6 \%)$, curious facts or unusual phenomena $(7 \%)$, create an original show atmosphere (for example, with the help of hip-hop music or friendly gatherings in the pub - 4\%).

- The authors do not impose restrictions on the recipient of their podcast, although special podcasts are created to popularize science among schoolchildren and students (2\%).

- All podcasts are a node in a hypermedia environment, connected with other nodes by a developed system of hyperlinks.

The analysis proved that the increasing prevalence of podcast in the popular science sphere is explained by a number of factors:

- $\quad$ on the one hand, the perception of a written text is much slower in comparison with an oral one, on the other, technical means development makes the subscription to the podcast quite easy. Thus, informing the user by means of podcasting becomes more accessible, faster and easier. Nowadays a new term "enhanced podcast" has appeared meaning a podcast containing hyperlinks, images, etc. synchronized to the audio information.

- listeners become a party of interpersonal communication not with a virtual author, but with a real person, get an opportunity to draw their own conclusions on the basis of the sounding speech, which is more expressive, emotional, having a strong impact on the addressee.

- $\quad$ any podcast is mostly interviews and discussions, i.e. a dialogue or a polylogue. The material is presented in the form that facilitates the perception of new information by means of questions, paraphrases, exemplifications, comments, etc.

\section{EXPERIMENTAL STUDY 2}

\section{Methods and Materials}

For a detailed analysis, we selected podcasts for 2005-2017 of the English-language site of the popular science magazine Nature. [http://www.nature.com/nature/podcast/index.html due to several reasons.

Firstly, this podcast is released every week since 2005, with all issues stored in the archive and available for analysis; it is free and quite popular. Each podcast in the format of a radio program is thematically linked to the journal, released during the week, and highlights the problems raised in it. The hosts invite leading scientists and researchers to comment on or present a discovery, research or a problem.

Secondly, being a part of the site http://www.nature.com, the podcast exists in a hypermedia environment, it is connected by a system of links with printed publications, other pages of this site, other sites, therefore, it is a valuable source of interdiscursive characteristics.

Thirdly, from the point of view of goals, a format and highlighted themes, this podcast is typical for podcasts of popular science sphere. It is polythemic, addressed to a wide range of listeners (no restrictions on age, education, 
profession, interests), aims at promoting scientific research as well as informing the listener about the most important achievements and searching for solutions to pressing interdisciplinary problems. Each transmission lasts 20-35 minutes and has a fairly rigid pre-established structure.

We aimed to identify structural peculiarities of podcasts (tapescripts and audio texts were compared); to define functions, themes and interrelations of their structural units and to consider functioning of Nature Podcast as a node in hypermedia environment.

\section{Results and Discussion}

The podcasts topics are directly connected with the theme of the journal Nature. It should be noted that the sections presented by the authors do not coincide with the traditional scientific areas and reflect the interdisciplinary policy of this publication. The theme of the podcast as a whole is reflected in the announcement of the podcast on the website of Nature, and in more detail in the podcast. Each podcast contains interviews as well as comments on research in various fields.

The structure of the podcast corresponds to the time frame (the volume of the audio file), as well as the target setting of the authors. The set characteristics of the program are reproduced in each podcast, which facilitates semantic perception of new information for the listeners forecasting the order of semantic blocks.

Each Nature podcast consists of defined blocks, containing information of a particular type and having a number of recurring formal characteristics. Podcasts are mainly heterogeneous, include passages with various aims (for example, advertisement, greeting, informing, announcement), modes (description, narration, reasoning, definition, explanation), methods of producing, duration, numbers of speakers, focus on different listeners. According to their functions the blocks can be divided into structural units forming the podcast "frame" (advertising, greeting, ending, slogan, names of speakers, farewell), forming connections within the programme (announcements, links to the interview) and bearing the main content of the podcast (interview, public speech).

Nature website archive contains text records of most podcasts (tapescript), a comparison of which with the sounding material made it possible to find a number of features related to the functioning of the podcast in a hypermedia environment.

The text record of the podcast (tapescript) on the Nature website does not include such features of the speakers' sounding speech as hitches, repetitions, hesitation pauses; punctuation marks do not always reflect the segmentation of the sounding speech by the speaker, there are no indications of the tract (phone), noises during recording. This greatly facilitates the visual perception of the text, bringing its characteristics closer to the journal article-interview.

However, the tapescript contains a number of structural elements that are missing in the recording and link the podcast to other hypermedia nodes.

First of all, this is an introduction that indicates the text type and the date of the podcast, providing a hyperlink to the podcast archive, where you can subscribe to regular releases, and describes the possibility of feedback. The changes apply only to the date of the podcast.

"This is a transcript of the May $31^{\text {st }}$ edition of the weekly Nature Podcast. Audio files for the current show and archive episodes can be accessed from the Nature Podcast index page (http://www.nature.com/nature/podcast), which also contains details on how to subscribe to the Nature Podcast for free, and has troubleshooting toptips. Send us your feedback to mailto: podcast@nature. com Oh."

[http://www.nature.com/nature/podcast/v447/n7144/nature-2007-05-31.html]

Another structural element that is not present in the speech is the hyperlink to the article on the problem discussed in each interview and public speech, for example, "Nature 447, 589-591 (31 May 2007)" - from the podcast on May 31, 2007.

Thus, the analysis of the podcast structure showed that it exists in a hypermedia environment, being its integral part, a node of hypermedia discourse. Investigating the links of this node with others, it is possible to construct an entire open network consisting of multimodal texts, in the perception of which several perceptual modalities are engaged (Sonin, 2006).

The connectors are in the form of links, hyperlinks, repetition of the title (key words of the title), the title of the journal, repetition of the research keywords, names of scientists, names of scientific institutions, the references to which come from each podcast (see Appendix).

\section{EXPERIMENTAL STUDY 3}

\section{Methods and Materials}

12 university teachers and 30 undergraduate students majoring in Linguistics (Translation Studies) were surveyed to analyze the peculiarities of podcasting usage and the role of multimedia in translators training. The experimental study consisted of 3 stages. At Stage 1 both the teachers and the students were asked to answer the questionnaire to find out their attitude to the usage of multimedia and podcasting in particular in translators' training. At Stage 2 the students were divided into 3 groups - A, B and C (10 students in each one). Group A was the control one, the classes were held according to the established practice. Group B fulfilled specific tasks based on the usage of audio and video files from Nature podcasts presenting the research in various field during one semester. On the whole, 15 podcasts were used. The tasks were aimed at introducing the topic, listening comprehension, discussion of the research, acquiring new vocabulary units, translating the audio or video text into Russian. Group C were given the same tasks together with the opportunity to surf the Internet looking for some information connected with the group project based on Nature publications. At Stage 3 the final assessment was held testing the progress of all the students in acquiring new vocabulary, developing the skills of information search, summarizing and presenting their finding. The students from groups B and C and the teachers were asked to estimate their experience in podcasting usage. 


\section{Results and Discussion}

The analysis of the survey showed that most teachers are not aware of the benefits of podcasting in teaching practice, though the students would like to be able to use mobile and online podcasting during the classes. They pointed out the diversity of topics covered in popular science podcasts and the way they facilitate mastering the specific sphere of communication vocabulary and system of concepts. However, being active participants of Stages 2 and 3 of the experimental study the teachers changed their mind, as the assessment procedure proved statistically relevant differences between groups $\mathrm{A}$ and $\mathrm{B} \backslash \mathrm{C}$ in terms of acquired vocabulary diversity and translation skills development and between Groups $\mathrm{A} \backslash \mathrm{B}$ and $\mathrm{C}$ as far as the speed of information search and presentation were concerned. The significance of the differences is confirmed by testing using criterion $3 \sigma$, where $\sigma$ is a selective quadratic deviation of tangents of the slope angles of the curve on the segment.

The study confirmed the results of Walls, Kucsera, Walker, Acee, McVaugh, \& Robinson, D. H. (2010), Pegrum, Bartle, \& Longnecker (2015) and Heilesen (2010) where the influence of podcasting on the changes of educational environment was investigated and showed the positive evaluation of podcasting integration on the final output. The final survey demonstrated that the podcast in the popular scientific sphere had got popular with university teachers and students, which is explained by the following factors:

- informing the user becomes more accessible, quicker and easier;

- the listener takes part in interpersonal communication not with a virtual author, but with a real person, gets the opportunity to make his own conclusions based on sounding speech, which is more expressive, emotional, and has a strong impact on the addressee;

- most podcasts are interviews and discussions, i.e. dialogues and polylogues, which facilitates the perception and processing of new information making it more structured by means of questions, paraphrasing, exemplification, clarifications, etc.;

- the teachers are provided with free didactic materials, which reflect modern findings in various fields of research;

- the users become active members of virtual scientific community, they are involved in various events, round-table talks, discussions, conferences, get information about new job vacancies.

\section{CONCLUSION}

The popular scientific discourse, reflecting the language practice in the field of popularization of scientific knowledge is characterized by a special set of features associated with typical communication situations, participants, goals, strategies, subjects of communication. An important feature of popular science discourse is that this type of discourse intersects with a huge number of others: pedagogical, political, advertising, gaming, computer, media. This is due precisely to the fact that popular science publications, programs and Internet sites set themselves a whole system of goals.

Specific virtual space, which acts as the real abode of real phenomena, which in reality are not represented together. The hypertext information model, proposed back in the $80 \mathrm{~s}$ and based on the hypothesis that the processing and generation of ideas by the human brain is associative, is increasingly recognized as a structure for the effective representation and transfer of knowledge. A hypertext system containing a network of nodes (fragments, modules, frames) and the associated links create a multidimensional information space adequate to the deep structure of the ideas processing by the human brain.

New virtual environment for intercultural interaction and cooperation is emerging nowadays.

Openness of the hypermedia discourse, the absence of a rigid hierarchy, the orientation toward interpersonal and specialized communication contribute not only to the global spread of innovative technologies that facilitate virtual communication, but also change the structural characteristics of the popular science discourse itself.

The importance of systematizing the goals and trends of the development of the popular science discourse is essential for deep understanding of the specifics of discourse structures, the dynamic aspect of the functioning of linguistic means, and the internal mechanisms of communication. The further study of popular science discourse, the generalization of the data obtained is not only important for the development of communicative and pragmatic linguistics, but can also be used in distance education, cross-cultural scientific communication.

\section{ACKNOWLEDGMENTS}

The publication has been prepared with the support of the "RUDN University Program 5-100".

\section{REFERENCES}

Gürsul, F., \& Canim, S. (2013). Knowledge management in the information age: Benefits and challenges of using podcasting as an educational tool. In Knowledge Management and Communication in the Information Age (pp. 1-12). Nova Science Publishers, Inc. Retrieved from http://www.scopus.com/inward/record. url?eid=2s2.084895365216\&partnerID=tZOtx3y1

Heilesen, S. B. (2010). What is the academic efficacy of podcasting? Computers and Education, 55(3), 1063-1068. https://doi.org/10.1016/j.compedu.2010.05.002

King, K. P., \& Gura, M. (2009). Podcasting for teachers : using a new technology to revolutionize teaching and learning. Emerging technologies for evolving learners (Vol. Rev 2, p. 288).

Charlotte, N.C.: Information Age Pub. Heilesen, S. B. (2010). What is the academic efficacy of podcasting? Computers and Education, 55(3), 1063-1068. https:// doi.org/10.1016/j.compedu.2010.05.002

Ono, Y., \& Ishihara, M. (2010). Examination of the podcasting system in second language acquisition. In Proceedings $-9^{\text {th }}$ IEEE/ACIS International Conference 
on Computer and Information Science, ICIS 2010 (pp. 540-545). https://doi.org/10.1109/ICIS.2010.139

Pearce, K., \& Scutter, S. (2010). Podcasting of health sciences lectures: Benefits for students from a non-English speaking background. Australasian Journal of Educational Technology, 26(7), 1028-1041.

Pegrum, M., Bartle, E., \& Longnecker, N. (2015). Can creative podcasting promote deep learning? The use of podcasting for learning content in an undergraduate science unit. British Journal of Educational Technology, 46(1), 142-152. https://doi.org/10.1111/bjet.12133

Russell, N. (2009). Communicating science: Professional, popular, literary. Communicating Science: Professional, Popular, Literary (pp. 1-324). Cambridge University Press. https://doi.org/10.1017/CBO9780511803918
Sava, M. (2011). Public understanding of science: science PR and popular culture. Romanian Journal of Journalism \& Communication, 6(1), 5-14.

Sonin, A. G. (2006). Modeling of mechanisms of polycode texts understanding: thesis. doctor of Philology: 10.02.19. - Moscow.

Stupina T. L. (2006). The Basics of using podcasting in the educational process: a methodological guide. Irkutsk: IGLU.

Walls, S. M., Kucsera, J. V., Walker, J. D., Acee, T. W., McVaugh, N. K., \& Robinson, D. H. (2010). Podcasting in education: Are students as ready and eager as we think they are? Computers and Education, 54(2), 371-378. https://doi.org/10.1016/j.compedu.2009.08.018.

\section{APPENDIX}

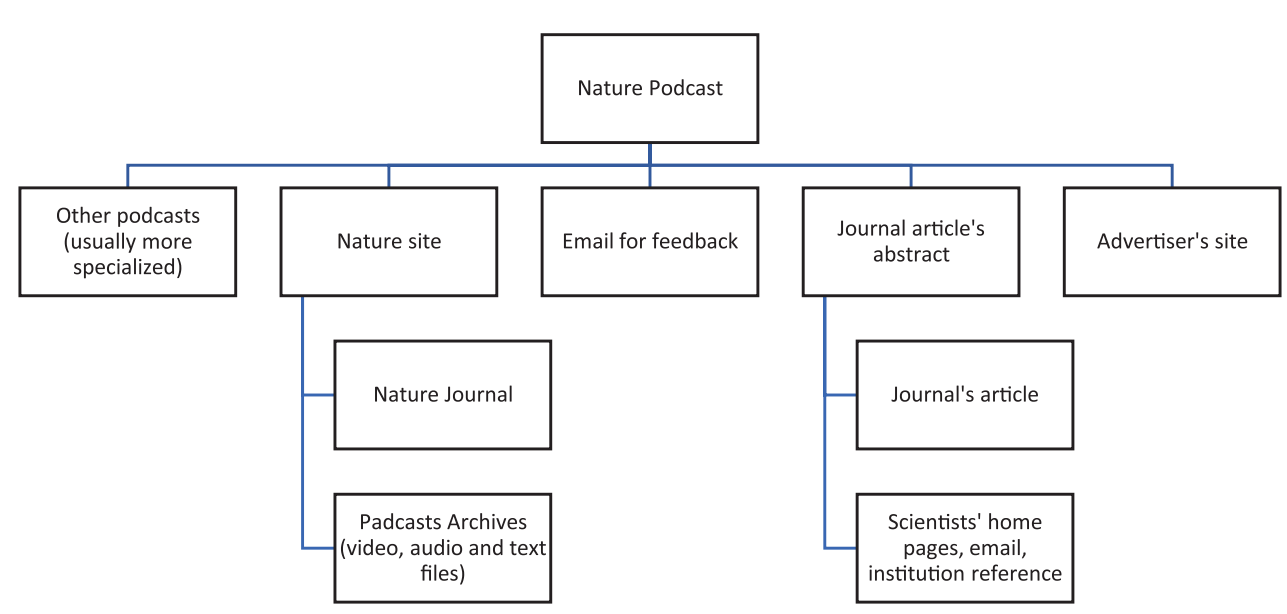

A hypermedia Nature podcast network with nodes of the first and second levels referenced from each podcast. 